\title{
3Y-TZP dip-coated with Zn-containing calcium silicate layers: development and characterization
}

\author{
Y.L. Bruni ${ }^{1,2 *}$, M.P. Albano ${ }^{1,2}$ \\ ${ }^{1}$ Centro de Tecnología de Recursos Minerales y Cerámica, CCT-La Plata CONICET, CICPBA, \\ CC 49 (B1897ZCA), M.B. Gonnet, Buenos Aires, Argentina \\ ${ }^{2}$ Universidad Nacional de La Plata, Facultad de Ciencias Exactas, La Plata, Buenos Aires, Argentina
}

\begin{abstract}
Coating layers based on $\mathrm{Ca}_{3} \mathrm{Si}_{3} \mathrm{O}_{9}, \mathrm{Ca}_{2} \mathrm{ZnSi}_{2} \mathrm{O}_{7}$, and $\mathrm{ZnSiO}_{4}$ on $3 \mathrm{Y}-\mathrm{TZP}$ ceramics were obtained by the dip coating process, using $\mathrm{SiO}_{2}-\mathrm{CaO}-\mathrm{P}_{2} \mathrm{O}_{5}-\mathrm{ZnO}$ glass suspensions with $\mathrm{Zn}$ contents in the range of 0-20 mol\%. The influence of the $\mathrm{Zn}$ content in the dip coating slips, the slip solid loading, and the 3Y-TZP surface porosity on the layer formation rate was studied. The Zn content of the dip coating slips as well as the slip solid loading greatly affected the slip viscosity, and consequently the liquid entrainment mechanism at the initial stage. The low dissolution rate of $20 \mathrm{~mol} \% \mathrm{Zn}$-containing slips decreased the dip coating slip viscosity, whereas the lower stability of $10 \mathrm{~mol} \% \mathrm{Zn}$-containing slips increased the slip viscosity. A significant increase in the initial layer thickness was produced either by using $10 \mathrm{~mol} \% \mathrm{Zn}$-containing slips or by increasing the slip solid loading. The casting rate for longer immersion times was markedly accelerated by increasing the 3 Y-TZP surface porosity. Sintered layers based on $\mathrm{ZnSiO}_{4}$ having the lowest thickness values were produced using the glass containing $20 \mathrm{~mol} \% \mathrm{Zn}$. On the other hand, the 0 and $10 \mathrm{~mol} \% \mathrm{Zn}$-containing glass produced thicker sintered layers mainly composed of $\mathrm{Ca}_{3} \mathrm{Si}_{3} \mathrm{O}_{9}$ and $\mathrm{Ca}_{2} \mathrm{ZnSi}_{2} \mathrm{O}_{7}$, respectively.
\end{abstract}

Keywords: biomaterials, 3 Y-TZP coated with Zn-containing calcium silicate, dip coating process, layer growth rate.

\section{INTRODUCTION}

Yttria-partially stabilized zirconia (3Y-TZP) is a ceramic widely used for dental and orthopedic applications owing to its excellent mechanical performance and biocompatibility $[1,2]$. These properties combined with excellent aesthetics extended its application in dental crowns [3]. The use of Zn-containing glasses and glass-ceramics as coatings on 3 Y-TZP is an approach to impart bioactive and antibacterial properties to the ceramic surface. Previous studies [4-6] have reported that $\mathrm{Zn}$ addition in silicate glasses retarded the glass degradation preventing bacterial infections. $\mathrm{Zn}$ is an essential component in the human bone and also stimulates bone formation in vitro and in vivo; in this sense, a Zn deficiency has been related to abnormal bone growth. In fact, $\mathrm{Zn}$ reduces bone resorption and accelerates the bone healing process, promoting osteoinductive properties [7-9]. One additional advantage of $\mathrm{Zn}$-containing silicate glasses over $\mathrm{Zn}$-free glasses is their superior mechanical strength [10]. Therefore, studies regarding the development and characterization of $\mathrm{Zn}$-substituted calcium silicate ceramics, such as $\mathrm{Ca}_{2} \mathrm{ZnSi}_{2} \mathrm{O}_{7}$, have been conducted in recent years [11, 12]. Several formulations of bioactive glasses doped with $\mathrm{Zn}$ have been obtained by the sol-gel method, and their in vitro bioactivity has been extensively studied [13,14].

Ceramic layers on 3Y-TZP substrates can be developed by the dip coating process. The formation of a layer on the porous substrate surface by dip coating is a combination of

*yesibruni@hotmail.com

Dhttps://orcid.org/0000-0002-0312-9251 the liquid entrainment mechanism at the initial stage, and the slip casting mechanism for dipping times $>0$. In this work, ceramic layers based on calcium silicate non-substituted and substituted by $\mathrm{Zn}$ with different thicknesses were obtained by immersing porous $3 \mathrm{Y}-\mathrm{TZP}$ disks into $\mathrm{SiO}_{2}-\mathrm{CaO}-\mathrm{P}_{2} \mathrm{O}_{5}-$ $\mathrm{ZnO}$ glass slips with $\mathrm{Zn}$ contents in the range of $0-20 \mathrm{~mol} \%$. The influence of the $\mathrm{Zn}$ content in the dip coating slips, the slip solid loading, and the 3Y-TZP surface porosity on the layer formation rate was investigated. Special emphasis was given to the $\mathrm{Zn}$ content of the dip coating suspensions and its influence on the thickness and composition of the sintered layer.

\section{MATERIALS AND METHODS}

Substrate preparation and characterization: 3Y-TZP disks were obtained by slip casting, using a commercial $3 \mathrm{~mol} \%$ $\mathrm{Y}_{2} \mathrm{O}_{3}$ partially stabilized zirconia powder $\left(\mathrm{d}_{50}=0.40 \mu \mathrm{m}\right.$, ZirPro, Saint-Gobain). 44 vol\% aqueous 3Y-TZP slips were prepared in an ultrasonic bath, by dispersing the powder in distilled water with $0.4 \mathrm{wt} \%$ of ammonium polyacrylate dispersant (PN, Duramax D 3500, Rohm \& Haas) at pH 9. Thereafter the slips were poured into molds to obtain green disks of $2 \mathrm{~cm}$ in diameter. The disks were dried at $100^{\circ} \mathrm{C}$ for a day, followed by heating at 1000 and $1300{ }^{\circ} \mathrm{C}$ for $2 \mathrm{~h}$ with a heating rate of $10{ }^{\circ} \mathrm{C} \cdot \mathrm{min}^{-1}$. The bulk density of the 3Y-TZP disks was measured by the ASTM C20 standard method. The relative density of 3 Y-TZP was determined using a theoretical density value of $6.05 \mathrm{~g} / \mathrm{cm}^{3}$. The surface microstructure of the $3 Y$-TZP substrates was observed by scanning electron microscopy (SEM) using a Quanta 200 (FEI) microscope. 
Glass synthesis and characterization: three glasses with compositions $59 \mathrm{SiO}_{2}-(36-\mathrm{x}) \mathrm{CaO}-5 \mathrm{P}_{2} \mathrm{O}_{5}-\mathrm{xZnO}$ (mol\%), with $\mathrm{x}=0,10$, and 20 , were prepared by the sol-gel method. The different glasses were nominated as SCP-0Zn, SCP$10 \mathrm{Zn}$, and SCP-20Zn in relation to their respective zinc content. Tetraethyl orthosilicate (TEOS) was added to 0.1 $\mathrm{M} \mathrm{HNO}_{3}$ solution to undergo acid hydrolysis; the mixture was magnetically stirred for $60 \mathrm{~min}$. This was followed by the addition of triethyl phosphate (TEP), $\mathrm{Ca}\left(\mathrm{NO}_{3}\right)_{2} \cdot 4 \mathrm{H}_{2} \mathrm{O}$, and $\mathrm{Zn}\left(\mathrm{NO}_{3}\right)_{2} \cdot 6 \mathrm{H}_{2} \mathrm{O}$, with 45 min interval between each addition to allow each reagent to react. Finally, the whole mixture was further stirred for $60 \mathrm{~min}$ to complete the hydrolysis. The synthesized solution was saved in a sealed container for 10 days at room temperature until the gel was formed. Then, the gel was dried at $70{ }^{\circ} \mathrm{C}$ for 3 days and $110{ }^{\circ} \mathrm{C}$ for 2 days, followed by calcination at $700{ }^{\circ} \mathrm{C}$ for $24 \mathrm{~h}$ to eliminate residual nitrates and stabilize the glass phase. The stabilized glass powders were milled by attrition milling using isopropyl alcohol for $3 \mathrm{~h}$ to obtain an average particle diameter of $3.0 \mu \mathrm{m}$. Afterward, the powder was dried at $60{ }^{\circ} \mathrm{C}$ for $24 \mathrm{~h}$. The crystalline phases were analyzed by powder X-ray diffraction (XRD), using a diffractometer (D2, Brucker) with $\mathrm{CuK} \alpha$ radiation and Ni filter in the $15-60^{\circ}$ $2 \theta$ range. Differential thermal analysis (DTA) of the glass powders was carried out in the air, using a thermal analyzer (STA 409, Netzsch) at a heating rate of $10{ }^{\circ} \mathrm{C} \cdot \mathrm{min}^{-1}$. The BET surface area $\left(\mathrm{S}_{\mathrm{BET}}\right)$ and the pore size distribution curves of the stabilized glass powders were evaluated using a pore analyzer (ASAP 2020, Micromeritics).

Processing of glass slips and dip coating: dip coating of SCP-0Zn, SCP-10Zn, and SCP-20Zn slips with different solid loading (10 and $15 \mathrm{vol} \%$ ) were prepared in an ultrasonic bath, using $0.4 \mathrm{wt} \% \mathrm{PN}$ as dispersant and $5 \mathrm{wt} \%$ polyvinyl alcohol as a binder. Steady flow curves of shear stress versus shear rate were obtained using a concentric cylinder viscometer (VT550, Haake) at room temperature. A coaxial cylinder system with two gaps (sensor system NV, Haake) was used. Zeta potential as a function of $\mathrm{pH}$ curves were determined for $0.06 \mathrm{vol} \%$ suspensions with $0.4 \mathrm{wt} \% \mathrm{PN}$ at $\mathrm{pH} 3-12$. $\mathrm{HCl}$ or $\mathrm{NH}_{4} \mathrm{OH}$ solutions were used to adjust the pH. 10 and 15 vol\% glass slips with different compositions were allowed to settle under gravity for 3 days to determine the maximum packing fraction $\left(\phi_{\mathrm{m}}\right)$ as follows:

$$
\varnothing_{\mathrm{m}}=\frac{\mathrm{C}}{1-\left(\mathrm{H}_{1} / \mathrm{H}_{\mathrm{t}}\right)}
$$

where $\mathrm{H}_{1}$ is the liquid height above the solid sediment, $\mathrm{H}_{\mathrm{t}}$ is the total height of the suspension, and $\mathrm{C}$ is the volume fraction of solids. 3 Y-TZP disks were dipped into glass slips for different times at a constant immersion and withdrawal rate of $6 \mathrm{~mm} / \mathrm{s}$. The coated discs were dried at room temperature and then at $100{ }^{\circ} \mathrm{C}$. Finally, the sintered layers were obtained by heating at $1000{ }^{\circ} \mathrm{C}$ for $1 \mathrm{~h}$. Sections polished with diamonds of coated 3 Y-TZP disks were characterized by SEM. The sintered layer thickness was measured on different sites along the 3Y-TZP surface, and the reported thickness values were the average of at least thirty measurements.

\section{RESULTS AND DISCUSSION}

\section{Substrate and glass characterization}

The porosity of 3Y-TZP disks sintered at $1000{ }^{\circ} \mathrm{C}$ was $46.76 \%$; a lower porosity of $21.80 \%$ was measured at $1300{ }^{\circ} \mathrm{C}$, as expected. SEM micrographs of the top and bottom surfaces of $3 \mathrm{Y}-\mathrm{TZP}$ sintered at $1000{ }^{\circ} \mathrm{C}$ are shown in Fig. 1. During casting, the top surface was exposed to the atmosphere whereas the bottom one was in contact with the mold. The bottom surface appeared rough as a consequence of the roughness of the mold in contrast to the smooth top surface. Another difference between both surfaces was the coarser microstructure of the bottom one. As we have previously pointed out [15], this can be attributed to the settling of the large particles at the bottom surface during casting. Accordingly, the migration of the fine particles to the top surface resulted in a finer microstructure.

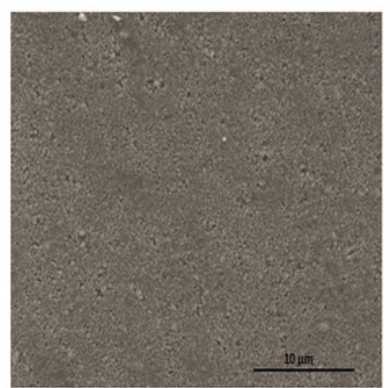

a)

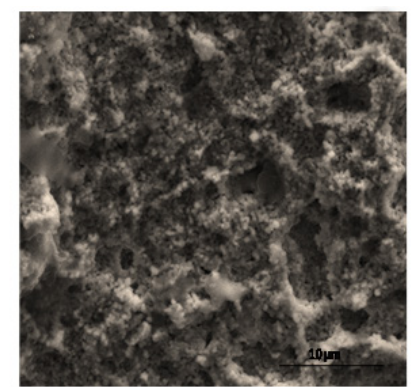

b)
Figure 1: SEM micrographs of the top (a) and bottom (b) surfaces of 3 Y-TZP sintered at $1000{ }^{\circ} \mathrm{C}$.

The XRD patterns of the three glasses calcined at $700{ }^{\circ} \mathrm{C}$ (Fig. 2a) showed a broad and diffused band at $17-25^{\circ} 2 \theta$ attributed to the amorphous $\mathrm{SiO}_{2}$ network, confirming the amorphous nature of the obtained glasses. However, poorly crystalline main phases were also detected in all the glasses as a consequence of the partial crystallization, which took place during heating at $700{ }^{\circ} \mathrm{C}$. They corresponded to the formation of $\mathrm{Ca}_{3} \mathrm{Si}_{3} \mathrm{O}_{9}$ (JCPDS 74-0874) for SCP-0Zn, $\mathrm{Ca}_{2} \mathrm{ZnSiO}_{7}$ (JCPDS 12-0453) for SCP-10Zn, and $\mathrm{ZnSiO}_{4}$ (JCPDS 37-1485) for SCP-20Zn. The presence of $\mathrm{Ca}_{2} \mathrm{ZnSiO}_{7}$ and $\mathrm{ZnSiO}_{4}$ in $\mathrm{SCP}-10 \mathrm{Zn}$ and SCP-20Zn, respectively, indicated that the $\mathrm{Zn}$ content in silicates increased at the expense of $\mathrm{Ca}$. The XRD patterns of the glass powders sintered at $1000{ }^{\circ} \mathrm{C}$ are shown in Fig. $2 \mathrm{~b}$. The main crystalline phase for SCP-0Zn was $\mathrm{Ca}_{3} \mathrm{Si}_{3} \mathrm{O}_{9}$, this one was accompanied by a secondary crystal phase of $\beta-\mathrm{CaSiO}_{3}$ and a small amount of amorphous $\mathrm{SiO}_{2}$. The 10 mol\% $\mathrm{Zn}$-containing glass produced $\mathrm{Ca}_{2} \mathrm{ZnSiO}_{7}$ as a major crystalline phase, along with minor amounts of quartz (JCPDS 85-0794) and cristobalite (JCPDS 71-0785) traces. The composition of SCP-20Zn showed the presence of $\mathrm{ZnSiO}_{4}$ and cristobalite; in addition to these phases, a small quantity of quartz and $\mathrm{Ca}_{2} \mathrm{ZnSiO}_{7}$ traces were detected. The diffraction peak of cristobalite at $2 \theta=21.95^{\circ}$ [(101) atomic 
plane] was overlapped with that of $\mathrm{ZnSiO}_{4}$ [(330) atomic plane]. The increase in the $\mathrm{Zn}$ content from 10 to $20 \mathrm{~mol} \%$ enhanced the formation of $\mathrm{Zn}$-rich phases, and also promoted the appearance of cristobalite at the expense of quartz.
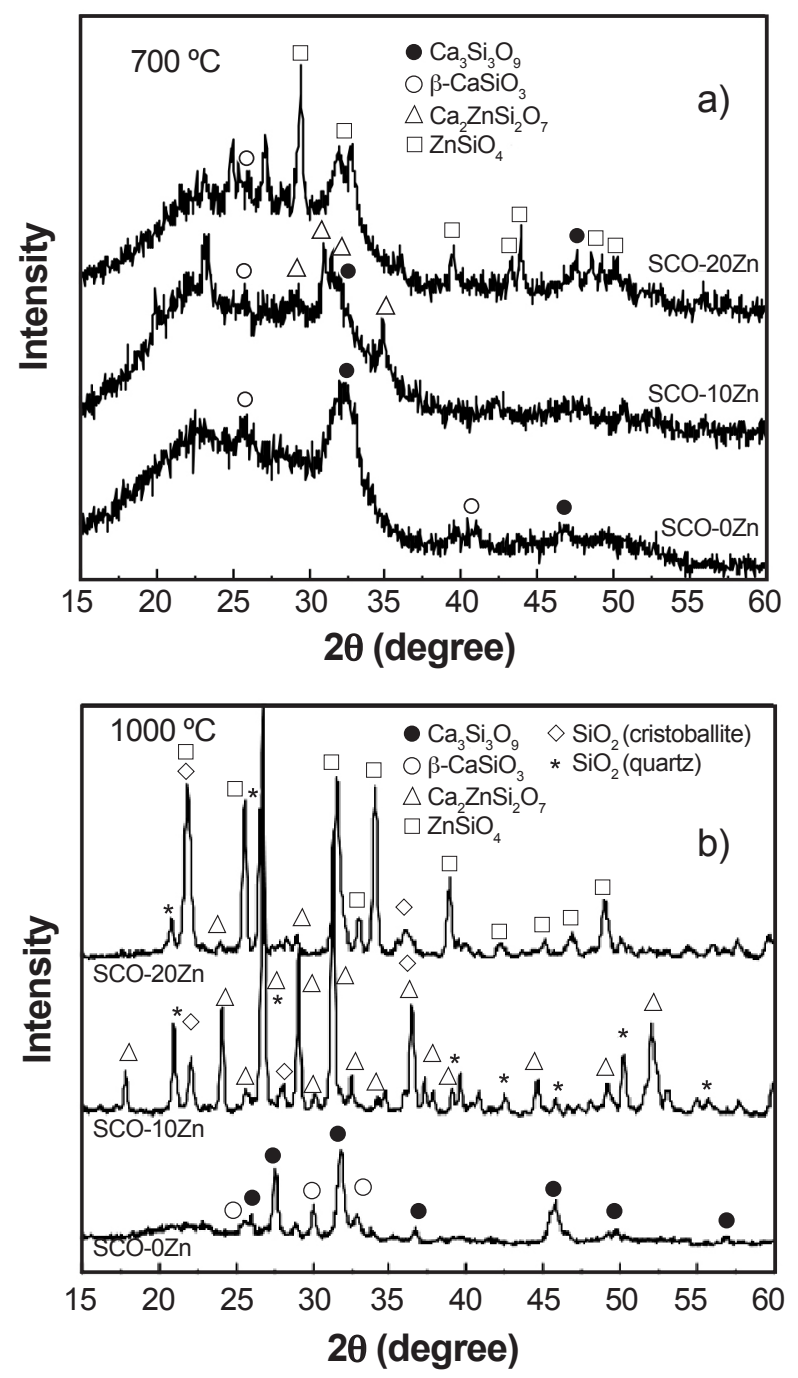

Figure 2: XRD patterns of the different glasses calcined at $700{ }^{\circ} \mathrm{C}$ (a) and sintered at $1000{ }^{\circ} \mathrm{C}$ (b).

The crystallization process of the glasses was analyzed by DTA. The DTA curves of the stabilized glass powders are shown in Fig. 3. Weak endothermic peaks corresponding to the glass transition and stronger ones associated with the fusion of crystalline phases appeared; the exothermic peaks corresponded to glass crystallization. The endothermic peaks that appeared at $100^{\circ} \mathrm{C}$ in all the glasses were associated with water loss. As the $\mathrm{Zn}$ content increased from 0 to $10 \mathrm{~mol} \%$ the glass transition temperature $\left(\mathrm{T}_{\mathrm{g}}\right)$ values decreased from 790 to $760{ }^{\circ} \mathrm{C}$. A greater $\mathrm{Zn}$ addition of $20 \mathrm{~mol} \%$ increased $\mathrm{T}_{\mathrm{g}}$ to $819^{\circ} \mathrm{C}$. For SCP-0Zn, the exothermic peaks at 863 and $903^{\circ} \mathrm{C}$ can be respectively assigned to the crystallization of $\beta-\mathrm{CaSiO}_{3}$ and $\mathrm{Ca}_{3} \mathrm{Si}_{3} \mathrm{O}_{9}$. In the case of $\mathrm{Zn}$-containing glasses, the exothermic peak at $858{ }^{\circ} \mathrm{C}$ corresponded to $\mathrm{Ca}_{2} \mathrm{ZnSiO}_{7}$ crystallization for SCP-10Zn, and the broad exothermic peak centered at $1035^{\circ} \mathrm{C}$ for SCP-20Zn was produced by the overlapping of the $\mathrm{ZnSiO}_{4}$ and cristobalite peaks. The effect of $\mathrm{Zn}$ addition on the $\mathrm{T}_{\mathrm{g}}$ values was closely related to the structural role of $\mathrm{Zn}$ in the glass powders. Several researchers $[11-13,16]$ reported that the partial substitution of Ca by $\mathrm{Zn}$ in the reference glass $(\mathrm{SCP}-0 \mathrm{Zn})$ produced modifications in the glass network connectivity. When the $\mathrm{Zn}$ acts as network former, it generates a more stable structure due to its incorporation into the glass network through covalent links between $\mathrm{SiO}_{4}$ tetrahedrons, increasing the number of bridging oxygen (BO) bonds. $\mathrm{Zn}^{2+}$ bivalent cations can be incorporated into the silicate network, forming Si-O-Zn bonds with two orthosilicate radical neighbors, according to the reaction:

$$
\mathrm{Si}-\mathrm{O}-\mathrm{Si}+\mathrm{ZnO} \rightarrow \mathrm{Si}-\mathrm{O}-\mathrm{Zn}-\mathrm{O}-\mathrm{Si}
$$

The greater network connectivity results in an increase in $\mathrm{T}_{\mathrm{g}}$. On the contrary, when the $\mathrm{Zn}$ plays the role of network modifier, it reduces the network connectivity by the increase of non-bridging oxygen (NBO) bonds and decreases the $\mathrm{T}_{g}$ value. Based on this discussion, our findings suggested that $\mathrm{Zn}$ acted as a network former in SCP-20Zn and a network modifier in SCP-10Zn.

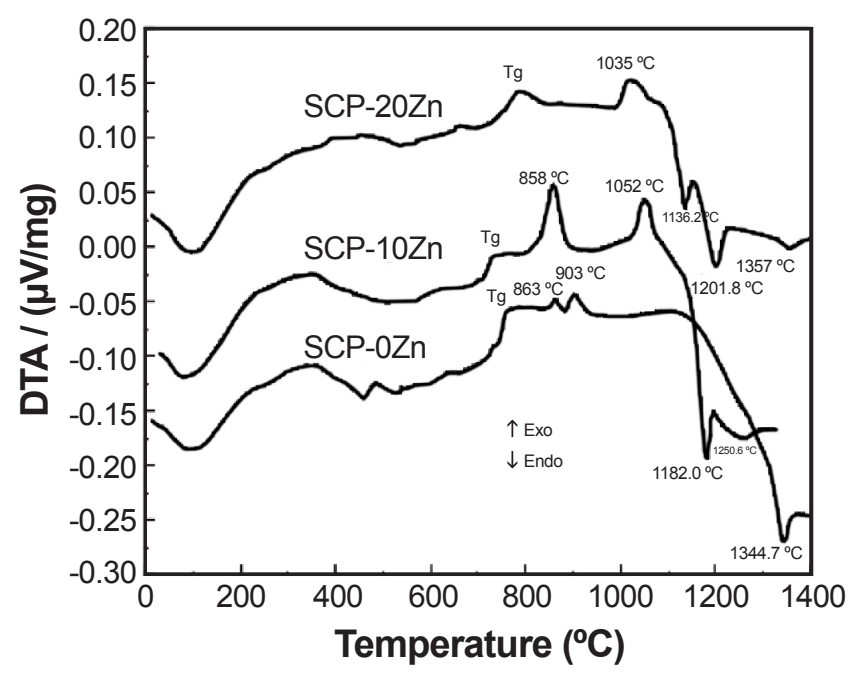

Figure 3: DTA curves of the stabilized glass powders.

Fig. 4 shows the nitrogen adsorption isotherm and the pore size distribution curves of the different glasses. The BET surface area $\left(\mathrm{S}_{\mathrm{BET}}\right)$ and the total pore volume $\left(\mathrm{V}_{\mathrm{p}}\right)$ of the glasses are, respectively, included in Figs. $4 a$ and $4 b$. The curves in Fig. 4a corresponded to type IV isotherms which are characteristics of a mesoporous structure. The porous structure of the glasses was generated by the gel formation process, in which the hydrolyzed precursors were linked by condensation. The evaporation of water and ethanol, retained in the capillaries of the structure, and the nitrate decomposition during heating contributed to the glass porosity. The glasses showed unimodal pore size distribution curves between 2 and $50 \mathrm{~nm}$ (Fig. 4b). Similar more frequent pore sizes in the range of 17.5 to $22 \mathrm{~nm}$ were found for the different glass compositions. The textural parameters 
depended on the zinc addition. The $10 \mathrm{~mol} \% \mathrm{Zn}$-containing glass exhibited a more porous network and consequently the largest $\mathrm{S}_{\mathrm{BET}}$. A similar effect has been previously reported by the low incorporation of $\mathrm{Zn}$ in mesoporous $\mathrm{SiO}_{2}-\mathrm{CaO}$ glasses [17, 18]. In contrast, the addition of $20 \mathrm{~mol} \% \mathrm{Zn}$ did not induce a substantial change in the textural parameters with respect to the reference glass without $\mathrm{Zn}$. Thus, the textural parameter results confirmed the structural role of $\mathrm{Zn}$ in the glasses. In SCP-10Zn, Zn assumed the role of a network modifier breaking the atomic array of $\mathrm{SiO}_{4}{ }_{4}^{4}$ structural units and generating defects and pores. This behavior was not found for SCP-20Zn since the $\mathrm{Zn}$ acted as a network former.
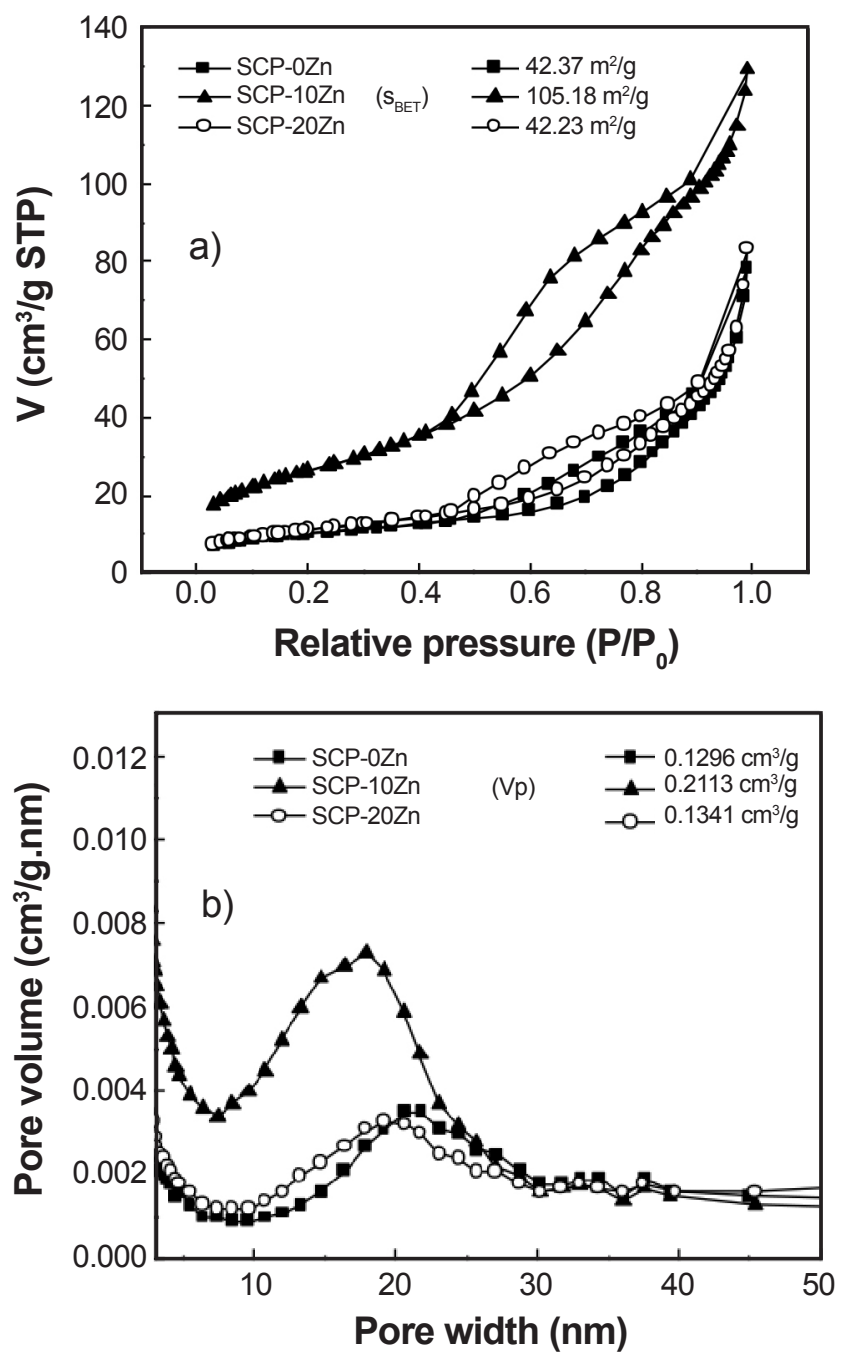

Figure 4: Nitrogen adsorption isotherm (a) and pore size distribution (b) curves of the different glasses.

\section{Slip properties of glass coating}

Fig. 5 shows the flow curves of viscosity as a function of shear rate for different glass compositions and solid loading. The viscosity of the coating slips significantly varied with the glass composition. This variation became greater with increasing the slurry solid loading. For each solid loading, the $10 \mathrm{~mol} \% \mathrm{Zn}$-containing glass slips showed the highest viscosity; on the contrary, the incorporation of $20 \mathrm{~mol} \% \mathrm{Zn}$ produced well-dispersed slips having the lowest viscosity values. The carboxylate groups negatively charged $\left(\mathrm{RCOO}^{-}\right)$of the $\mathrm{PN}$ polyelectrolyte at $\mathrm{pH} 8.5$ was adsorbed at the particle surface. The magnitude of the polyelectrolyte adsorption depends on the $\mathrm{pH}$ and the ionic strength of the suspensions. In order to get insight into the ionic strength of the slurries, the $\mathrm{pH}$ change with increasing glass concentration during the aqueous colloidal processing of 10 vol\% SCP-0Zn, SCP-10Zn, and SCP-20Zn slips is presented in Table I. $\mathrm{A}$ pH increment from 7.00 to $9.32,10.00$, and 8.60 was measured with the introduction of about $0.04 \mathrm{~g} / \mathrm{mL}$ of SCP$0 Z n, S C P-10 Z n$, and SCP-20Zn, respectively, to the aqueous solution. The $\mathrm{pH}$ remained nearly constant with further glass additions. It is well known [19-21] that the increase in $\mathrm{pH}$ upon immersion of glass to the aqueous solution can be related to an exchange reaction between $\mathrm{H}^{+}$from the solution and modifier cations (located at NBO bonds) from the glass. This exchange reaction produces cations leached out from the glass surface and $\mathrm{OH}^{-}$, leading to an increase in $\mathrm{pH}$ [19-21]. The smaller variation of $\mathrm{pH}$ in SCP-20Zn glass solutions indicated a lower cation release rate from the glass surface. A marked reduction in cation release from 45S5 glass with the substitution of $\mathrm{Ca}$ by $\mathrm{Zn}$ at $\mathrm{pH} \sim 7$ has been reported elsewhere [5,6]. In our study, the glass dissolution and the ion exchange reaction decreased with increasing the network connectivity. It has also been reported $[14,22]$ that in glasses with a $\mathrm{Zn}$ content higher than $10 \mathrm{~mol} \%$, the $\mathrm{Ca}^{2+}$ could be removed from NBO bonds by electrostatic forces derived from the presence of $\mathrm{ZnO}_{4}{ }^{2-}$ ions in the structure. In our study, the greater network connectivity and the capture of $\mathrm{Ca}^{2+}$ from NBO bonds could be responsible for the decrease in SCP-20Zn dissolution rate. On the other hand, a higher dissolution rate of SCP-10Zn with the corresponding increase in $\mathrm{pH}$ was found. Comparing SCP-10Zn with SCP0Zn, a similar ion-exchange reaction could be expected since $\mathrm{Ca}^{2+}$ in NBO bonds was replaced by $\mathrm{Zn}^{2+}$. However, the significantly higher $\mathrm{S}_{\mathrm{BET}}$ and $\mathrm{V}_{\mathrm{p}}$ of SCP-10Zn, with

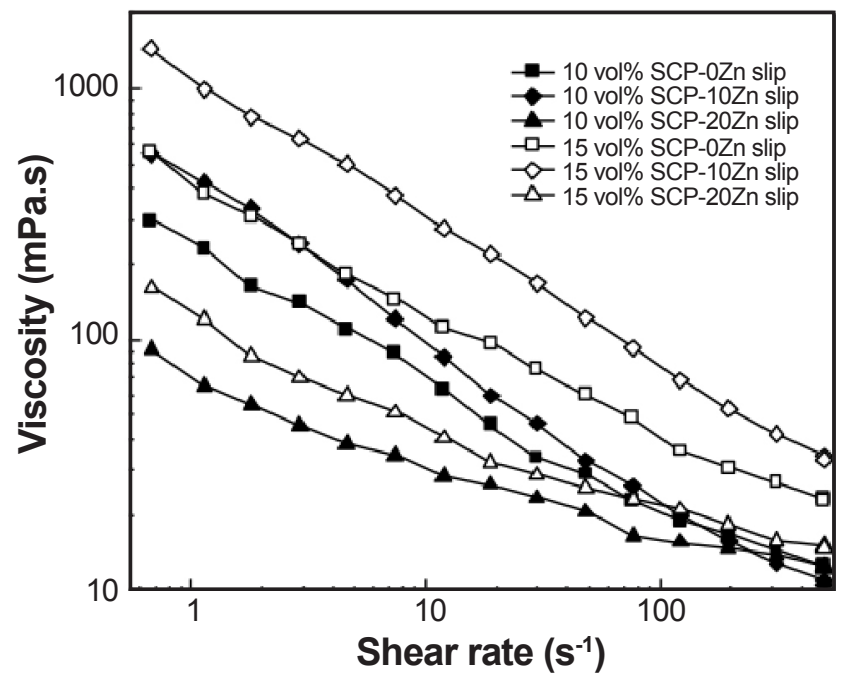

Figure 5: Flow curves of viscosity as a function of shear rate for different glass compositions and solid loadings. 
Table I - $\mathrm{pH}$ as a function of glass concentration during the aqueous colloidal processing of different $10 \mathrm{vol} \%$ slips.

\begin{tabular}{cccc}
\hline $\begin{array}{c}\text { Glass } \\
\text { concentration } \\
(\mathrm{g} / \mathrm{mL})\end{array}$ & SCP-0Zn & SCP-10Zn & SCP-20Zn \\
\hline 0 & 7.00 & 7.00 & 7.00 \\
0.040 & 9.32 & 10.00 & 8.60 \\
0.078 & 9.30 & 9.99 & 8.58 \\
0.122 & 9.29 & 10.03 & 8.61 \\
0.180 & 9.31 & 10.01 & 8.59 \\
0.253 & 9.30 & 10.02 & 8.62 \\
\hline
\end{tabular}

respect to those of SCP-0Zn, indicated a more open silicate network, which promoted the ion exchange reaction. SCP0Zn exhibited an intermediate glass dissolution rate between that of SCP-10Zn and SCP-20Zn.

In the colloidal processing of diluted 10 and $15 \mathrm{vol} \%$ slips, the separation distance between particles was large. In this condition, the electrostatic forces between particles provided by the PN adsorption could be considered as the main contribution to the slip stabilization. Some researchers $[23,24]$ have studied the $\mathrm{Ca}^{2+}$ effect on the adsorption of poly(acrylic acid) (PAA) dispersant on oxide surface, reporting that $\mathrm{Ca}^{2+}$ formed chemical complexes with PAA in the adsorbed polyacrylate layer. These complexes reduce the electrostatic charge of the adsorbed polymer and promote the $\mathrm{RCOO}^{-}$adsorption [24-26]. Therefore, the formation of complexes in the adsorbed layer increases the polymer adsorption leading to thick layers. In our study, the $\mathrm{Ca}^{2+}$ and $\mathrm{Zn}^{2+}$ leached out from the glass surface could form complexes with PN in the adsorbed layer, altering the net surface charge of the PN adsorbed-glass powders. Fig. 6 shows the curves of zeta potential as a function of $\mathrm{pH}$ of the different glass slips with $0.4 \mathrm{wt} \%$ PN. SCP-20Zn slip exhibited the highest negative zeta potential value in the alkaline $\mathrm{pH}$ range. This behavior was in accordance with the lower dissolution of SCP-20Zn glass (Table I). The lower cation release of SCP20Zn could result in thinner adsorbed layers with a higher net surface charge. The increase in the electrostatic repulsive interactions between particles led to low viscosity values of 10 and 15 vol\% SCP-20Zn slips. On the contrary, the higher $\mathrm{Ca}^{2+}$ and $\mathrm{Zn}^{2+}$ released from the SCP-10Zn surface produced thicker layers having lower net surface charge (Fig. 6).

The high $\mathrm{S}_{\mathrm{BET}}$ of SCP-10Zn glass powders could also contribute to increasing the slip viscosity. In general, the effective solid volume fraction of powders with high $\mathrm{S}_{\mathrm{BET}}$ is greater than the calculated volume fraction of solid, as a consequence of thicker hydrated and polyelectrolyte adsorbed layers [27]. In order to confirm this hypothesis, the values of maximum packing fraction $\left(\phi_{\mathrm{m}}\right)$ for 10 and 15 vol\% SCP-0Zn, SCP-10Zn, and SCP-20Zn slips were determined and presented in Table II. The lowest $\phi_{\mathrm{m}}$ value for SCP-10Zn slips at both solids loading indicated a higher solid sediment volume (Eq. A). Therefore, a larger

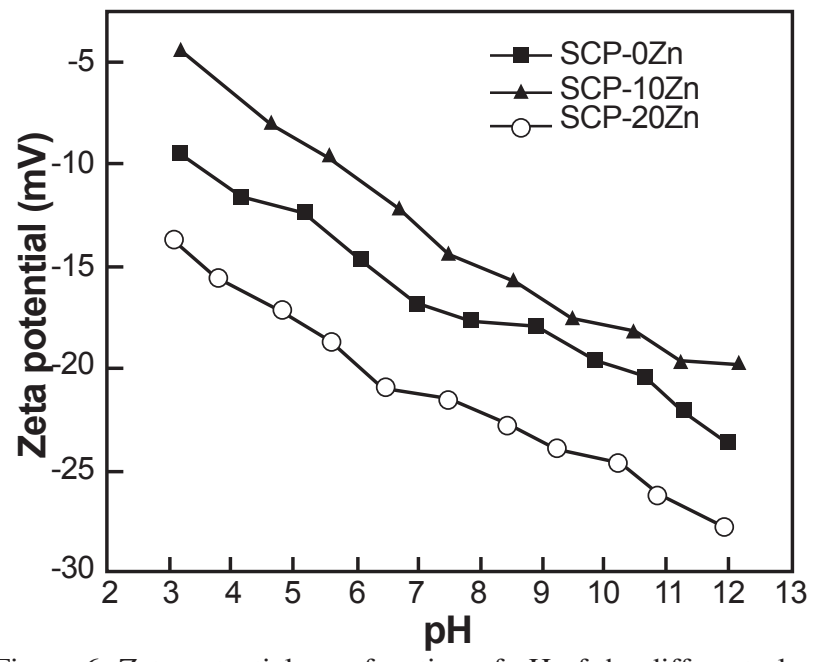

Figure 6: Zeta potential as a function of $\mathrm{pH}$ of the different glass slips with $0.4 \mathrm{wt} \% \mathrm{PN}$.

effective solid volume fraction of SCP-10Zn relative to that of SCP-0Zn and SCP-20Zn could be assumed. The lower electrostatic repulsion between particles together with the higher effective solid volume fraction of SCP-10Zn slips produced an increase in the slip viscosity. For each glass composition, the slip viscosity increased as the solid loading increased from 10 to $15 \mathrm{vol} \%$ due to greater particle and hydrodynamic interactions.

Table II - Maximum packing fraction, $\phi_{\mathrm{m}}(\%)$, as a function of the slip composition and solid loading.

\begin{tabular}{cccc}
\hline $\begin{array}{c}\text { Slip solid } \\
\text { loading } \\
\text { (vol\%) }\end{array}$ & SCP-0Zn & SCP-10Zn & SCP-20Zn \\
\hline 10 & 12.5 & 10.6 & 13.7 \\
15 & 18.7 & 15.4 & 20.3 \\
\hline
\end{tabular}

\section{Dip coating layers}

During the dip coating process, the flat substrate was immersed into the coating slip for different times; afterward, it was withdrawn from the suspension, leaving a layer on its surface. The initial stage of the dip coating process is known as the liquid entrainment mechanism. The initial thickness of the adhered layer $\left(\mathrm{H}_{0}\right)$ at a constant withdrawn speed $(\mathrm{v})$ can be expressed as the ratio between the viscous forces and the liquid surface tension $(\gamma)$ by [28-30]:

$$
\mathrm{H}_{0}=\mathrm{C}\left(\frac{\eta \cdot \mathrm{v}}{\gamma}\right)^{2 / 3}
$$

where $C$ is a constant and $\eta$ is the slip viscosity. A thin ceramic coating on the substrate surface was formed after the liquid evaporation from the adhered layer. At longer immersion times, the capillary filtration of the liquid through the pores on the sample surface generated a wet cake at the suspension-substrate interface. The final sintered film was 
obtained after heat treatment of the coated substrate. The layer growth under the capillary filtration driving force can be satisfactorily described by the slip casting model. Based on this model, the evolution of the sintered layer thickness $\left(\mathrm{H}_{\mathrm{s}}\right)$ with time is given by [28]:

$$
\mathrm{H}_{\mathrm{s}}=\mathrm{a}\left(\frac{\varepsilon \cdot \gamma \cdot \mathrm{K} \cdot \mathrm{t}}{\mu \cdot \beta \cdot r}\right)^{1 / 2}
$$

where a and $\beta$ are expressed as:

$$
\begin{aligned}
& a=\frac{\varphi}{\left(1-\varepsilon_{\mathrm{s}}\right)} \\
& \beta=\left(\frac{\varphi}{\varphi_{1}}\right)-1
\end{aligned}
$$

where $\phi$ is the volume fraction of particles in the coating slip, $\phi$ is the volume fraction of particles in the wet layer, $\varepsilon$ is the porosity of the substrate, $\varepsilon_{\mathrm{s}}$ is the porosity of the sintered layer, $\mu$ is the viscosity of the dispersion liquid, $r$ is the pore radius, $\mathrm{K}$ is the wet layer permeability, and $\mathrm{t}$ is the dipping time. According to Eq. D, the solid content of the slips, the substrate porosity, and the layer permeability have an important influence on the layer growth rate. Fig. 7a shows the experimental thickness of the sintered layer on the smooth surfaces as a function of dipping time for 3Y-TZP sintered at 1000 and $1300^{\circ} \mathrm{C}$ dip-coated in different suspensions. The layer thickness increased with dipping time up to reaching surface saturation at $120 \mathrm{~s}$. The thickest layer at $120 \mathrm{~s}(54 \mu \mathrm{m})$ was obtained for 3Y-TZP sintered at $1000{ }^{\circ} \mathrm{C}$ dip-coated in 15 vol\% SCP-10Zn slip. On the other hand, the thinnest layer $(17 \mu \mathrm{m})$ was found for 3Y-TZP sintered at $1300{ }^{\circ} \mathrm{C}$ immersed in $10 \mathrm{vol} \%$ SCP-20Zn slip. It can be noticed that for the same substrate and slip solid loading, the casting rate markedly varied with the $\mathrm{Zn}$ glass content. For 3Y-TZP sintered at $1000{ }^{\circ} \mathrm{C}$ dip-coated in 15 vol\% slips, layer thickness about $50 \%$ smaller was formed using SCP-20Zn dip coating slip in comparison to SCP-
$10 \mathrm{Zn}$ slip. The same tendency was found in the case of 3 Y-TZP sintered at $1300{ }^{\circ} \mathrm{C}$ dip-coated in 10 vol\% slips with different glass compositions; thus the layer growth rate was strongly dependent on the $\mathrm{Zn}$ content.

SEM images of 3 Y-TZP sintered at $1000{ }^{\circ} \mathrm{C}$ dip-coated in 10 vol\% SCP-10Zn and SCP-20Zn slips during 120 s (Fig. 8) confirmed the layer thickness results. Clearly, a lower layer thickness was obtained by using SCP-20Zn dip coating slips. Fig. $7 \mathrm{~b}$ presents the squared layer thickness versus dipping time for 3Y-TZP sintered at 1000 and $1300{ }^{\circ} \mathrm{C}$ dip-coated in different suspensions. The linear relation between the squared layer thickness and time indicated that the layer formation for $t>0$ followed the slip casting model (Eq. D). As mentioned, the first mechanism in the layer formation process (dipping time 0) was the liquid entrainment, which left a thin slurry film on the substrate surface. The initial layer thickness $\left(\mathrm{H}_{0}\right)$ was the intersection of the lines with the squared layer thickness axis in Fig. 7b. For identical substrate and slip solid loading, $\mathrm{H}_{0}$ varied with the $\mathrm{Zn}$ concentration of the dip coating slurries. The disks immersed in SCP-10Zn slips exhibited the highest initial layer thickness and the lowest one was found for SCP20Zn slips, having SCP-0Zn slips an intermediate $\mathrm{H}_{0}$ value. According to Eq. C, at a constant withdrawn rate, $\mathrm{H}_{0}$ was only influenced by the slip viscosity. Therefore, the variation of the initial thickness values with the $\mathrm{Zn}$ content of dip coating slips was in agreement with their respective slip viscosity values (Fig. 5). The lower viscosity of $20 \mathrm{~mol} \% \mathrm{Zn}$-containing slips produced thinner initial layers, whereas $10 \mathrm{~mol} \% \mathrm{Zn}$ containing slips having the highest viscosity resulted in thicker layers at the initial stage. Considering dipping times $>0$ in Fig. $7 \mathrm{~b}$, the $10 \mathrm{~mol} \% \mathrm{Zn}$-containing glass slip presented a slightly greater casting rate (greater line slope) in comparison to 0 and $20 \mathrm{~mol} \% \mathrm{Zn}$-containing slips, for the same substrate and slip solid loading. This result could be attributed to the lower $\phi_{\mathrm{m}}$ value of $10 \mathrm{~mol} \% \mathrm{Zn}$-containing slips, which increased the permeability and porosity of the wet layer, resulting in a higher casting rate (Eq. D).
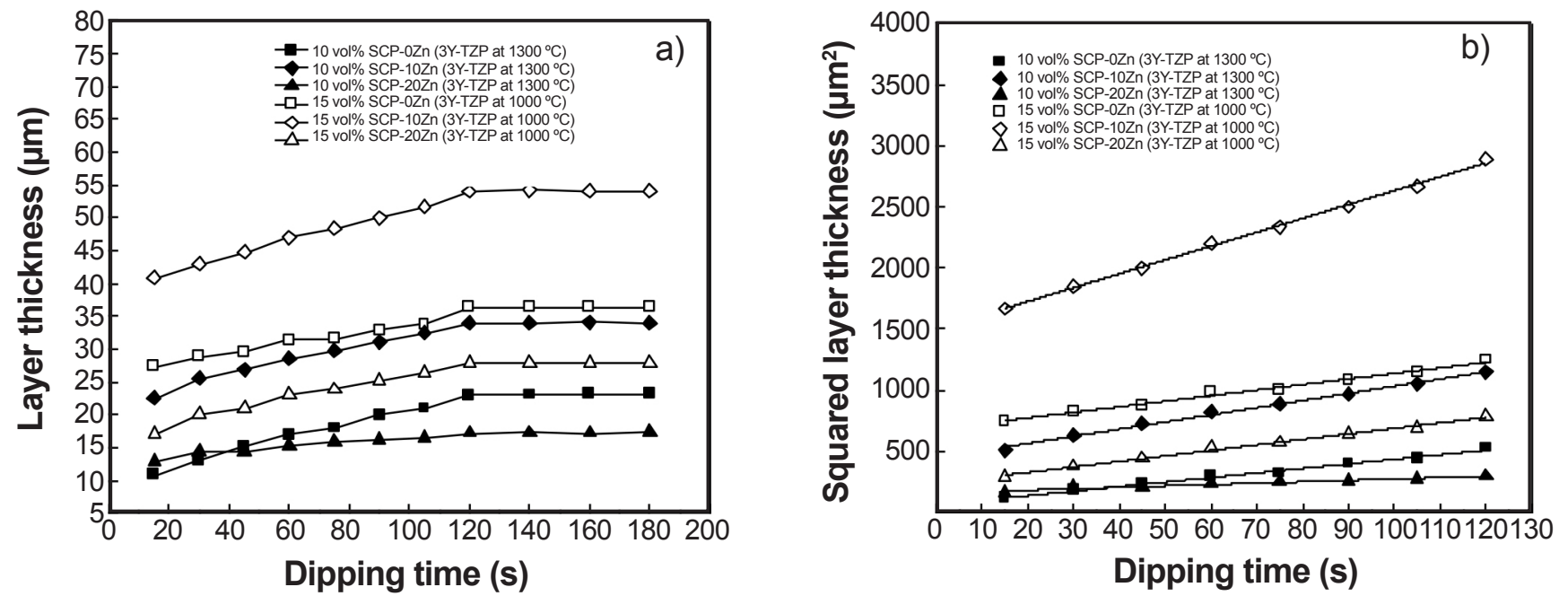

Figure 7: Linear (a) and squared (b) layer thickness on the smooth surfaces as a function of dipping time for 3 Y-TZP sintered at 1000 and $1300{ }^{\circ} \mathrm{C}$ dip-coated in different suspensions. 

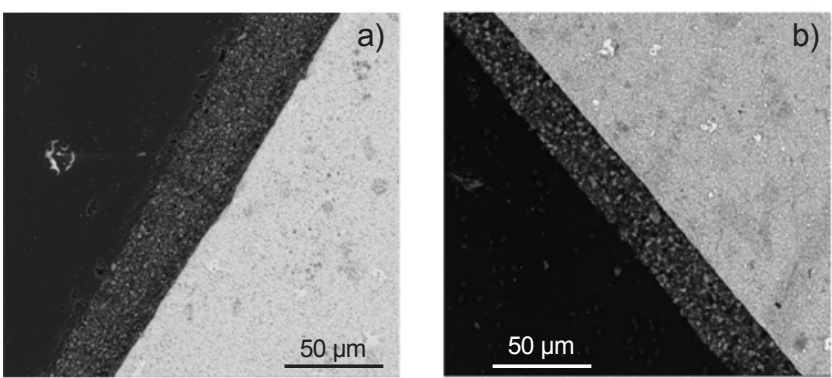

Figure 8: SEM images of 3Y-TZP samples sintered at $1000{ }^{\circ} \mathrm{C}$ dipcoated in different $10 \mathrm{vol} \%$ slips during $120 \mathrm{~s}$ showing the surface layers formed with SCP-10Zn (a) and SCP-20Zn (b) glass powders.

The effect of the 3Y-TZP surface porosity and the slip solid loading on the layer formation rate is shown in Fig. 9. As expected, identical slips and consequently slip viscosity produced layers with similar initial thickness irrespective of the 3Y-TZP surface porosity. However, the surface porosity of the substrate greatly affected the casting rate for longer immersion times. The greater surface porosity of 3Y-TZP sintered at $1000{ }^{\circ} \mathrm{C}$ markedly increased the casting rate (Eq. D). On the other hand, when the same substrate was used, a greater thickness at the initial stage was formed by increasing the slip solid loading. This behavior was attributed to the higher viscosity of $15 \mathrm{vol} \%$ slips relative to that of $10 \mathrm{vol} \%$ slips (Fig. 5). However, the casting rate for longer dipping times was not significantly altered with the increase in the slip solid content from 10 to $15 \mathrm{vol} \%$. It was expected that these stable suspensions produced a wet layer with similar permeability and therefore casting rate. In summary, a significant increase in the initial layer thickness was produced either by increasing the slip solid content or by using $10 \mathrm{~mol} \% \mathrm{Zn}$-containing glass slips. The casting rate was markedly accelerated by increasing the $3 \mathrm{Y}$-TZP surface porosity. A notable increase in the initial layer thickness followed by a less pronounced increase in the casting rate

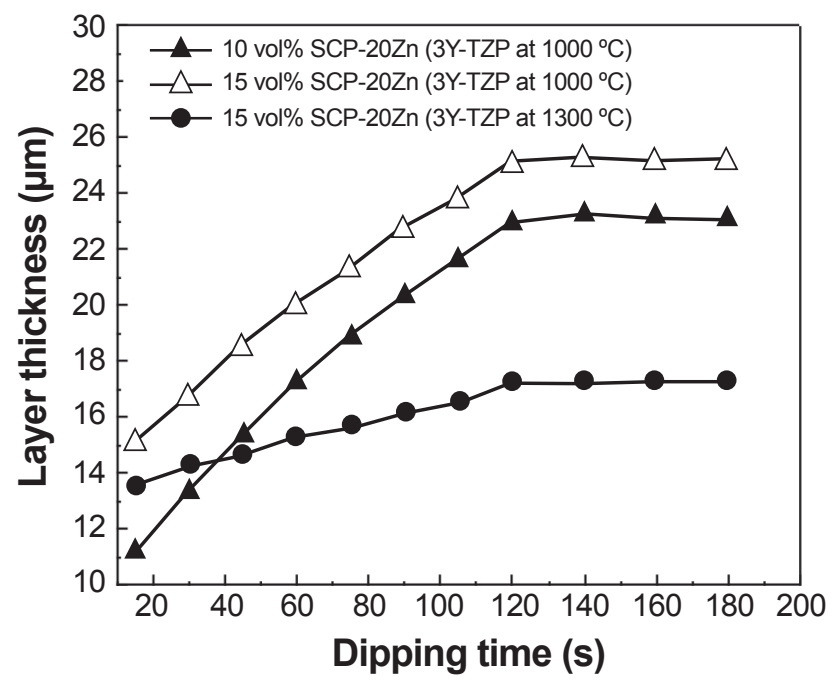

Figure 9: Layer thickness on the smooth surfaces as a function of dipping time for $3 \mathrm{Y}$-TZP sintered at $1000{ }^{\circ} \mathrm{C}$ dip-coated in SCP$20 \mathrm{Zn}$ slips with different solid loading, and 3Y-TZP sintered at different temperatures dip-coated in 15 vol\% SCP-20Zn slip. was found when 3 Y-TZP was dip-coated in $10 \mathrm{~mol} \% \mathrm{Zn}$ containing glass slips.

\section{CONCLUSIONS}

Coating layers based on $\mathrm{Ca}_{3} \mathrm{Si}_{3} \mathrm{O}_{9}, \mathrm{Ca}_{2} \mathrm{ZnSi}_{2} \mathrm{O}_{7}$, and $\mathrm{ZnSiO}_{4}$ on 3 Y-TZP ceramics were developed by the dip coating process. The influence of the $\mathrm{Zn}$ content in the dip coating slips, the slip solid concentration, and the 3Y-TZP surface porosity on the layer formation rate was evaluated. The $\mathrm{Zn}$ content of the dip coating slips as well as the slip solid loading greatly affected the slip viscosity, and consequently the liquid entrainment mechanism at the initial stage. The low dissolution rate of $20 \mathrm{~mol} \% \mathrm{Zn}$-containing slips markedly decreased the dip coating slip viscosity. Thinner initial layers were found either by using $20 \mathrm{~mol} \% \mathrm{Zn}$ containing slips or by decreasing the slip solid loading. For longer dipping times, the casting rate decreased by reducing the 3 Y-TZP surface porosity. The glass containing $20 \mathrm{~mol} \%$ $\mathrm{Zn}$ produced sintered layers mainly composed of $\mathrm{ZnSiO}_{4}$, having the lowest thickness values. On the other hand, the $10 \mathrm{~mol} \% \mathrm{Zn}$-containing slips produced thicker layers based on $\mathrm{Ca}_{2} \mathrm{ZnSi}_{2} \mathrm{O}_{7} \cdot \mathrm{Ca}_{2} \mathrm{ZnSi}_{2} \mathrm{O}_{7}$ and $\mathrm{ZnSiO}_{4}$ coatings on $3 \mathrm{Y}-\mathrm{TZP}$ would play an important role in wound healing, becoming promising ceramics for orthopedic and dental applications.

\section{REFERENCES}

[1] F. Chen, J.M. Wu, H.Q. Wu, Y. Chen, C.H. Li, Y.S. Shi, Int. J. Lightweight Mater. Manuf. 1 (2018) 239.

[2] Y. Zhang, B.R. Lawn, J. Dent. Res. 97 (2017) 1.

[3] C.H. Chin, A. Muchtar, C. Azhari, M. Razali, M. Aboras, Malaysian J. Anal. Sci. 20 (2016) 642.

[4] S.M. Rabiee, N. Nazparvar, M. Azizian, D. Vashaee, L. Tayebi, Ceram. Int. 41 (2015) 7241.

[5] M. Blochberger, L. Hupa, D. Brauer, Biomed. Glasses 1 (2015) 93.

[6] G.S. Lázaro, S.C. Santos, C.X. Resende, E.A. Santos, J. Non-Cryst. Solids 386 (2014) 19.

[7] M. Yamaguchi, K. Inamoto, Y. Suketa, Biochem. Pharmacol. 36 (1987) 4007.

[8] M. Yamaguchi, K. Inamoto, Y. Suketa, Res. Exp. Med. 186 (1986) 337.

[9] S.A. Seyedmajidi, M. Seyedmajidi, A. Moghadamnia, Dent. Res. J. 11 (2014) 475.

[10] A. Karthika, L. Kavitha, M. Surendiran, S. Kannan, D. Gopi, RSC Adv. 5 (2015) 47341.

[11] J. Ma, B.X. Huang, X.C. Zhao, C.Z. Wang, Ceram. Int. 43 (2017) 14851.

[12] J. Ma, B.X. Huang, X.C. Zhao, X.H. Hao, C.Z. Wang, Mater. Lett. 236 (2019) 566.

[13] I. Atkinson, E.M. Anghel, L. Predoana, O.C. Mocioiu, L. Jecu, I. Raut, C. Munteanu, D. Culita, M. Zaharescu, Ceram. Int. 42 (2016) 3033.

[14] A. Balamurugan, G. Balossier, S. Kannan, J. Michel, A.H.S. Rebelo, J.M.F. Ferreira, Acta Biomater. 3 (2007) 255.

[15] Y.L. Bruni, L.B. Garrido, M.P. Albano, L.N. Teixeira, 
P.T. de Oliveira, A.L. Rosa, Ceram. Int. 41 (2015) 14212.

[16] M. Abeer, El-Kady, F.A. Ashraf, Ceram. Int. 38 (2012) 1195.

[17] A.J. Salinas, S. Shruti, G. Malavasi, L. Menabue, M. Vallet-Regí, Acta Biomater. 7 (2011) 3452.

[18] L. Courtheoux, J. Lao, J.M. Nedelec, E. Jallot, J. Phys. Chem. C 112 (2008) 13663.

[19] M. Bini, S. Grandi, D. Capsoni, E. Saino, L. Visai, J. Phys. Chem. C 113 (2009) 8821.

[20] S. Kapoor, A. Goel, A. Tilocca, V. Dhuna, G. Bhatia, K. Dhuna, J.M.F. Ferreira, Acta Biomater. 10 (2014) 3264.

[21] J.E. Shelby, Introduction to glass science and technology, $2^{\text {nd }}$ ed., Royal Soc. Chem. (2005).

[22] S. Shahrabi, S. Hesaraki, S. Moemeni, M. Khorami, Ceram. Int. 37 (2011) 2737.
[23] J.A. Lewis, J. Am. Ceram. Soc. 83 (2000) 2341.

[24] L. Dupont, A. Foissy, R. Mercier, B. Mottet, J. Colloid Interf. Sci. 161 (1993) 455.

[25] J. Sun, L. Bergstrom, L. Gao, J. Am. Ceram. Soc. 84 (2001) 2710.

[26] N. Sebastian, B. George, B. Mathew, Polym. Degrad. Stab. 60 (1998) 371.

[27] G. Tari, M.F. Ferreira, O. Lyckfeldt, J. Eur. Ceram. Soc. 18 (1998) 479.

[28] Y. Gu, G. Meng, J. Eur. Ceram. Soc. 19 (1999) 1961.

[29] C.J. Brinker, G.C. Frye, A.J. Hurd, C.S. Ashley, Thin Solid Films 201 (1991) 97.

[30] T. Schneller, R. Wasser, M. Kosec, D. Payne (Eds.), "Chemical solution deposition of functional oxide thin films", Springer-Verlag (2013).

(Rec. 20/04/2021, Rev. 12/07/2021, Ac. 16/07/2021) 